\title{
32. LATE NEOGENE PALEOENVIRONMENT STUDIES ON CARBONATE CONTENT, GRAIN SIZES, AND DISSOLUTION, CORES 1-57 (DSDP SITE 397)
}

\author{
Maria Bianca Cita, Department of Geology and Paleontology, University of Milano, Italy \\ and \\ Giuseppe Spezzibottiani, Centro Alpi CNR, University of Milano, Italy
}

\section{BACKGROUND AND MOTIVATION}

The purpose of this study is to investigate the evolution of ocean paleoenvironment during the approximately $7 \mathrm{~m} . \mathrm{y}$. whose sedimentary expression is represented by the hemipelagites contained in Cores 397-1 to 397-57. The carbonate content and two different sediment fractions were measured from 260 samples.

Samples were taken at regularly spaced intervals in the continuously cored section. One sample from each 1.5-meter section was collected, usually the interval 50 to $52 \mathrm{~cm}$ from the top of the section. Due to the unusually high sedimentation rate, averaging $7 \mathrm{~cm} / 1000$ years for the interval under discussion, we have a data point (where core recovery was good) for every $\sim 20,000$ years. In the cores with poor recovery (e.g., Cores 1, 35, $40,46,50$, and 51 from Hole 397 ), the control is less complete.

The same set of samples measured for carbonates and for two grain sizes was also used for quantitative micropaleontological studies on four selected test intervals (Cita and Colombo, this volume) and for investigations on stable isotopes (Shackleton and Cita, this volume). This multiple use of sample material ensures the best correlation of results.

Pelagic sediments deposited on the ocean floor above the carbonate compensation depth (CCD) and the lysocline are usually rich in biogenic carbonates, and carbonate curves recording changes in biogenic productivity have been shown to be significant in terms of paleoclimatic indications (Hays et al., 1969; Shackleton and Opdyke, 1976; inter alias). A positive correlation between carbonate curves and curves of stable isotopic ratio of $\delta^{18} \mathrm{O}$ has been recorded in the upper Pleistocene of the South Atlantic (Johnson et al., 1977) and in the North Atlantic (Thiede, 1977).

The sequence penetrated at Site 397, however, represents a special case because of (1) its setting on a continental rise at a distance of only 60 miles from the coast, (2) the high sedimentation rate, and (3) the presence of surface boundary currents and of upwelling in the area (Thiede, 1977).

Under these circumstances, carbonate maxima should be considered more reliable than carbonate minima, since the latter might result from volcanic input and/or from terrigenous dilution. Nevertheless, we cannot rule out the possibility that part of the carbonates are clasts, especially in the intervals where the coarse fractions are relatively abundant.
Pelagic sediments rich in biogenic carbonates deposited on the ocean floor above the CCD but close to the lysocline are subject to dissolution at depth by undersaturated bottom waters. Several procedures have been used in the last 10 years to evaluate the degree of dissolution undergone by biogenic sediments, starting from the classical work by Berger (1968). The following comments apply:

Berger (1968) used as "solution index" the preservation aspect of foraminifers. This procedure is easy to apply, but qualitative in nature and the results obtained by different workers cannot be compared. Further complicating interlab comparisons are the differing sample handling techniques by various laboratories.

Workers at Kiel University (e.g., Diester-Haass, 1976; Sarnthein, this volume; Diester-Haass, this volume) use the ratio between entire tests and fragmented tests of planktonic foraminigers based on countings. This procedure is easy to apply and quantitative, but depends strongly on the processing technique (see above). Also, fragmentation of planktonic foraminiferal tests is not entirely controlled by dissolution at depth, but can also result from sedimentary processes.

Cita (1971) used a quantitative but time-consuming procedure that is unsuitable for large numbers of samples. This procedure is based on percentages of entire tests versus fragmented tests by weight, and requires picking of all unbroken tests, then making two sets of weightings. With this procedure, one can calculate the mean weight of a planktonic foraminiferal test (entire), which is also a meaningful parameter to evaluate the degree of dissolution.

Shackleton and Opdyke (1976) used the sediment fraction greater than $180 \mu \mathrm{m}$ (by weight) as the "dissolution index." This procedure is easy, immediate, and not highly dependent upon processing techniques. The large-size sediment fraction usually consists only of whole tests of the larger-size species.

Evaluating the advantages and disadvantages of the different procedures, we decided to use a modified version of the last one.

\section{PROCEDURES}

The carbonate content of the bulk sediment was measured (one gram of the dried bulk sediment) using a modified calcimeter (model Pizzarelli). The bulk sediment was weighed with a precision analytical balance before being processed with hydrogen peroxide. A 200 $\mu \mathrm{m}$ and a $93 \mu \mathrm{m}$ sieve were used. We weighed the two 
sediment fractions that we obtained: $<200 \mu \mathrm{m}=$ Fraction A, and 200 to $93 \mu \mathrm{m}=$ Fraction B. Percentage to the total sample was calculated for each fraction.

The grain sizes selected differ from those routinely used by DSDP. The purpose of our selecting different fractions was to avoid meaningless duplication with the grain-size analysis of other laboratories (e.g., see Diester-Haass, this volume). The larger fraction we chose approaches the $180 \mu \mathrm{m}$ used by Shackleton and Opdyke (1976) to evaluate dissolution zones. Moreover, it has been shown (Gerhard Lutze, personal communication, 1977) that downslope displacement of benthic foraminifers is commonly recorded in a nearby piston core (Meteor 12309), only in the finer fractions, whereas the fraction $>250 \mu \mathrm{m}$ shows no evidence of downslope displacement.

The benthic foraminifers picked for isotopic studies (Shackleton and Cita, this volume) and the planktonic forms picked for quantitative micropaleontological studies (Cita and Colombo, this volume) are all from the sediment Fraction A. The inverse of this fraction $(100-\mathrm{A})$ is used here as the "dissolution index."

The difference between Fraction A and Fraction B also provides valuable information on sediment dissolution. This parameter is here termed the "dissolution measure."

\section{RESULTS}

The results obtained from the 259 calcimetric analysis and the $260 \times 3$ weightings (given as Fraction A, Fraction B, and Fraction A + B) are represented graphically in Figure 1 (see Figure pocket at end of this volume, Part I). Figure 1 presents the columnar log of Cores $397-1$ to $397-59$, the paleomagnetic stratigraphy (after Hamilton, this volume), some seismic horizons identified with erosional surfaces (Ryan, this volume), and the zonal boundaries (after Cita; Salvatorini; Cepek Wind; Mazzi; Rio and Raffi, all, this volume).

\section{Carbonates}

The mean value of the 259 measurements, 57.18 per cent, is indicated by a continuous line in Figure 1. The minimum value (27\%) was recorded in Section 397-54-4 (upper Miocene), the maximum value (77\%) in Section 397-45-2 (uppermost Miocene).

The carbonate curve of Figure 1 shows a number of clearly defined cycles. Peaks and troughs are accentuated in the "Glacial" Quaternary, corresponding to the Brunhes Paleomagnetic Epoch. Carbonate cycles are also easily recognizable lower in the section, in the lower Quaternary, the Pliocene, and the upper Miocene.

A definite trend toward increasing carbonate values is recorded in the lower Pliocene. Carbonate values decrease strongly downhole in the upper Miocene, where we have evidence of dissolution at depth, as shown by extensive fragmentation of the foraminiferal tests.

\section{"Dissolution Index"}

As stated above, we use here as "dissolution index" the inverse of Fraction A (100-Fraction A). The mean value of Fraction A is 0.99 per cent (dashed line in Figure 1); thus, the average "dissolution index" is 99.1 .

The maximum value of Fraction A (4.4\%) was recorded in the topmost sample, (i.e., Core 397-1-1); it is sub-Recent, and its "dissolution index" is 95.6. The minimum value recorded for Fraction A (yielding the maximum "dissolution index") is in the lower Pliocene Sample 397-38-6, and is 0.01 per cent and 99.99 per cent, respectively. Similar extreme values were recorded in Cores 397-52 and 397-53 (upper Tortonian).

The "dissolution index" increases downhole as a function of depth. This trend has the same sign as the carbonate curve (see above) and the isotopic curve (see Shackleton and Cita, this volume), which both tend to increase downwards (the isotopic ratio is less positive), at least down to the Miocene/Pliocene boundary. In detail, the grain-size curve (i.e., the inverse of the "dissolution index") of Fraction A and the carbonate curve tend to have an opposite trend, which agrees with quantitative observations on Core V 28-239 from the equatorial Pacific (Shackleton and Opdyke, 1976).

\section{"Dissolution Measure"}

The "dissolution measure" is the difference in percentage weight of size Fractions A and B. Fraction A is generally smaller than Fraction B, i.e., the "dissolution measure" is negative. The differences are relatively small in the Quaternary and upper Pliocene. Lower in the section they increase and the averages calculated every 50 meters (see Figure 2) differ by a factor of two or more in the sections below 500 meters sub-bottom (upper Tortonian). This is a clear and unambigulous indication of dissolution at depth, since Fraction A is essentially biogenic and consists of whole tests of largesized, mostly planktonic foraminifers. When subject to strong dissolution, they fragment; thereby becoming part of the smaller Fraction B, which consequently increases.

The rare intervals where the "dissolution measure" is positive clearly represent an aberration in the oceanographic regime at the drillsite location (see Cita and Ryan, this volume).

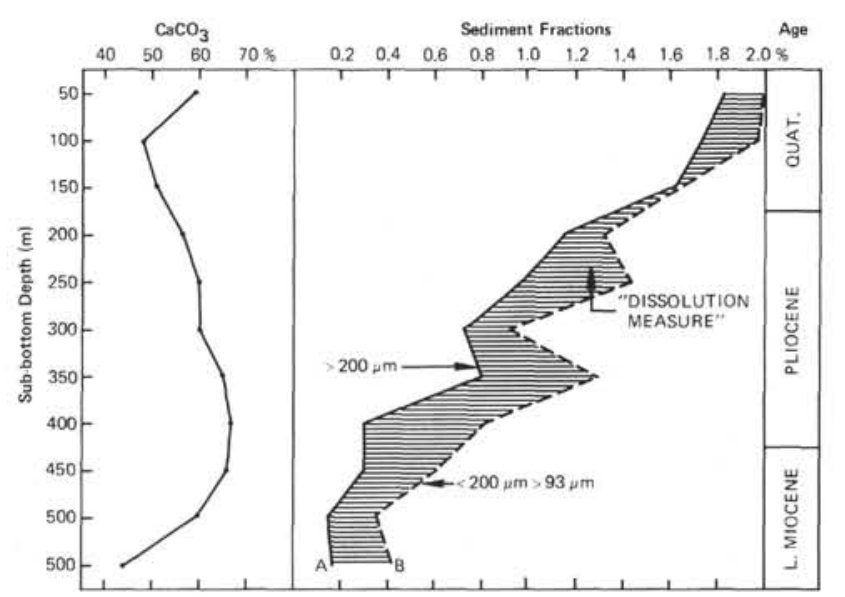

Figure 2. Mean values of carbonates (column to the left) and of sediments Fractions $A$ and $B$ (columns to the right) calculated for every successive 50-meter interval. 


\section{DISCUSSION}

As previously mentioned, the distance between two consecutive samples, even with complete core recovery, is such that not all climatic events of the last 7 m.y. can be recorded. This means that the numerous peaks and troughs shown in Figure 1 cannot be considered a faithful record of all the carbonate and dissolution cycles recorded in the North Atlantic. Consequently, we refrain from attempting a correlation with the numbered stages recorded in the equatorial Pacific (Hays et al., 1969; Shackleton and Opdyke, 1976) notwithstanding the good biostratigraphic control and the satisfactory paleomagnetic calibration at Site 397 (see Mazzei et al., this volume; Burckle, this volume). Simply stated, the sampling frequency is inadequate for reliable correlations.

Instead, we concentrated our efforts in on eliminating the sampling disturbance, smoothing the curves to identify major trends, and understanding their paleoceanographic significance.

\section{Construction of 11 Data Point Curves (with mean values every $50 \mathrm{~m}$ interval)}

We first calculated the mean values for the data points obtained for every 50-meter interval. The number of measurements for each interval ranges from 10 to 31 .

Tables 1 to 4 plot the number of samples, mean value, standard deviation, standard mean deviation, standard normal distribution, and mean confidence interval for the carbonate content (Table 1), Fraction A (Table 2), Fraction B (Table 3), and Fractions A + B (Table 4).

Figure 2 records the changes observed in the mean value of carbonates (column to the left) and of sediment Fractions A and B (column to the right). The smoothed curves of Figure 2 entirely mask the paleoclimatic history of the "glacial" Quaternary, but substantiate observations on the reversal of the trend shown by the carbonate curve at the Miocene/Pliocene boundary near 400 meters sub-bottom.
Definition and Significance of "Grain-Size Ratio" and of "Dissolution Ratio"

A relationship appears in these curves (Figure 2) between the two grain-sizes here being considered, as well as between the larger grain size (Fraction A) and the $\mathrm{CaCO}_{3}$ content. Therefore, we defined two additional parameters, as follows:

$$
\begin{aligned}
& \text { "grain-size ratio" }=\frac{\text { Fraction } \mathrm{B}}{\text { Fraction } \mathrm{A}} \\
& \text { "dissolution ratio" }=\frac{\text { Fraction } \mathrm{A}}{\mathrm{CaCO}_{3}}
\end{aligned}
$$

These parameters are plotted in Table 5 and graphically represented by the 11 data points curves of Figure 3 (mean values calculated every $50 \mathrm{~m}$ ).

Both "grain-size ratio" and "dissolution ratio" display significant trends. The former is fairly steady in the upper 300 meters, then decreases lower in the section, with large variations. This trend is even clearer on the curve of 57 data points (see Figure 4).

The marked increase downward in "grain-size ratio" coincides with the depth where strong evidence of dissolution is visible in the sediments. Consequently, we can state that a value $>2$ for "grain-size ratio" is per se an indication of dissolution.

The "dissolution ratio" requires some background explanations, concerning (a) sediment burial and the effect of compaction on physical properties, (b) known changes in the CCD in the North Atlantic during the Neogene, and (c) relationships between climatic changes and CCD.

Strong changes in "dissolution ratio," as here defined, are recorded in the upper part of the section (see Figures 4 and 5), where the diagenetic potential of the sediments is highest. (Reference is made to Schlanger and Douglas, 1974, who gave an excellent summary of diagenetic processes in pelagic sediments.) The ampli-

TABLE 1

Fundamental Statistical Parameters Calculated for Each 50-Meter Interval

\begin{tabular}{|c|c|c|c|c|c|c|c|c|}
\hline \multirow{2}{*}{$\begin{array}{c}\begin{array}{c}\text { Sub-Bottom } \\
\text { Depth } \\
\text { (m) }\end{array} \\
0-50\end{array}$} & \multirow{2}{*}{$\begin{array}{c}\begin{array}{c}\text { Number of } \\
\text { Samples } \\
(n)\end{array} \\
25\end{array}$} & \multirow{2}{*}{$\begin{array}{c}\begin{array}{c}\text { Mean Value } \\
(M)\end{array} \\
58.28\end{array}$} & \multirow{2}{*}{$\begin{array}{c}\begin{array}{c}\text { Standard } \\
\text { Deviation } \\
(s)\end{array} \\
10.67\end{array}$} & \multirow{2}{*}{$\begin{array}{c}\begin{array}{c}\text { Standard } \\
\text { Mean Deviation } \\
\left(S_{m}\right)\end{array} \\
2.13\end{array}$} & \multicolumn{2}{|c|}{$\begin{array}{l}\text { Standard Normal } \\
\text { Distribution } \\
(M \pm t . s)\end{array}$} & \multicolumn{2}{|c|}{$\begin{array}{c}\text { Mean Confidence } \\
\text { Interval } \\
\left(M \pm t . S_{m}\right)\end{array}$} \\
\hline & & & & & 80.31 & 36.25 & 62.68 & 53.87 \\
\hline $50-100$ & 29 & 48.23 & 8.39 & 1.56 & 65.42 & 31.04 & 51.42 & 45.03 \\
\hline $100-150$ & 30 & 50.96 & 7.36 & 1.34 & 66.02 & 35.90 & 53.71 & 48.21 \\
\hline $150-200$ & 31 & 56.70 & 7.78 & 1.40 & 72.58 & 40.82 & 59.55 & 53.85 \\
\hline $200-250$ & 28 & 60.04 & 7.94 & 1.50 & 76.34 & 44.00 & 63.12 & 56.96 \\
\hline $250-300$ & 28 & 60.04 & 7.51 & 1.42 & 75.45 & 44.64 & 62.95 & 57.13 \\
\hline $300-350$ & 17 & 65.20 & 5.05 & 1.22 & 75.91 & 54.49 & 67.80 & 62.60 \\
\hline $350-400$ & 17 & 67.16 & 5.08 & 1.23 & 77.94 & 56.38 & 69.77 & 64.54 \\
\hline $400-450$ & 23 & 66.27 & 6.26 & 1.30 & 79.26 & 53.29 & 68.98 & 63.56 \\
\hline $450-500$ & 10 & 59.27 & 5.67 & 1.79 & 72.09 & 46.44 & 63.32 & 55.21 \\
\hline$>500$ & 21 & 44.16 & 10.34 & 2.26 & 65.73 & 22.58 & 48.86 & 39.45 \\
\hline
\end{tabular}
Relating to the $\mathrm{CaCO}_{3}$ Content (Cores 397-1 to 397-57) 
TABLE 2

Fundamental Statistical Parameters Calculated for Each 50-Meter Interval Concerning Sediment Fraction A $(>200 \mu \mathrm{m})$

\begin{tabular}{|c|c|c|c|c|c|c|c|c|}
\hline \multirow{2}{*}{$\begin{array}{c}\text { Sub-Bottom } \\
\begin{array}{c}\text { Depth } \\
\text { (m) }\end{array} \\
0-50\end{array}$} & \multirow{2}{*}{$\begin{array}{c}\text { Number of } \\
\text { Samples } \\
(n)\end{array}$} & \multirow{2}{*}{$\begin{array}{c}\text { Mean Value } \\
(M) \\
1.830\end{array}$} & \multirow{2}{*}{$\begin{array}{c}\begin{array}{c}\text { Standard } \\
\text { Deviation } \\
(s)\end{array} \\
0.771\end{array}$} & \multirow{2}{*}{$\begin{array}{c}\begin{array}{c}\text { Standard } \\
\text { Mean Deviation } \\
\left(S_{m}\right)\end{array} \\
0.154\end{array}$} & \multicolumn{2}{|c|}{$\begin{array}{c}\text { Standard Normal } \\
\text { Distribution } \\
(M \pm t . s)\end{array}$} & \multicolumn{2}{|c|}{$\begin{array}{c}\text { Mean Confidence } \\
\text { Interval } \\
\left(M \pm t . S_{m}\right)\end{array}$} \\
\hline & & & & & 3.42 & 0.24 & 2.15 & 1.51 \\
\hline $50-100$ & 29 & 1.718 & 0.731 & 0.136 & 3.23 & 0.23 & 2.01 & 1.45 \\
\hline $100-150$ & 31 & 1.620 & 0.750 & 0.135 & 3.15 & 0.09 & 1.89 & 1.34 \\
\hline $150-200$ & 31 & 1.154 & 0.482 & 0.087 & 2.14 & 0.17 & 1.33 & 0.98 \\
\hline $200-250$ & 28 & 0.980 & 0.461 & 0.087 & 1.92 & 0.03 & 1.16 & 0.80 \\
\hline $250-300$ & 28 & 0.731 & 0.372 & 0.070 & 1.49 & - & 0.87 & 0.59 \\
\hline $300-350$ & 17 & 0.806 & 0.427 & 0.104 & 1.71 & - & 1.02 & 0.59 \\
\hline $350-400$ & 17 & 0.304 & 0.169 & 0.041 & 0.66 & - & 0.39 & 0.22 \\
\hline $400-450$ & 22 & 0.305 & 0.242 & 0.051 & 0.81 & - & 0.41 & 0.20 \\
\hline $450-500$ & 10 & 0.150 & 0.163 & 0.051 & 0.52 & - & 0.27 & 0.03 \\
\hline$>500$ & 21 & 0.172 & 0.087 & 0.019 & 0.35 & - & 0.21 & 0.13 \\
\hline
\end{tabular}

TABLE 3

Fundamental Statistical Parameters Calculated for Each 50-Meter Interval Concerning Sediment Fraction B (200 to $93 \mu \mathrm{m})$

\begin{tabular}{|c|c|c|c|c|c|c|c|c|}
\hline \multirow{2}{*}{$\begin{array}{c}\text { Sub-Bottom } \\
\text { Depth } \\
\text { (m) }\end{array}$} & \multirow{2}{*}{$\begin{array}{c}\begin{array}{c}\text { Number of } \\
\text { Samples } \\
(n)\end{array} \\
25\end{array}$} & \multirow{2}{*}{$\begin{array}{c}\begin{array}{c}\text { Mean Value } \\
(M)\end{array} \\
2.047\end{array}$} & \multirow{2}{*}{$\begin{array}{c}\begin{array}{c}\text { Standard } \\
\text { Deviation } \\
(s)\end{array} \\
0.641\end{array}$} & \multirow{2}{*}{$\begin{array}{c}\begin{array}{c}\text { Standard } \\
\text { Mean Deviation } \\
\left(S_{m}\right)\end{array} \\
0.128\end{array}$} & \multicolumn{2}{|c|}{$\begin{array}{l}\text { Standard Normal } \\
\text { Distribution } \\
(M \pm t . s)\end{array}$} & \multicolumn{2}{|c|}{$\begin{array}{c}\text { Mean Confidence } \\
\text { Interval } \\
\left(M \pm t . S_{m}\right)\end{array}$} \\
\hline & & & & & 3.37 & 0.72 & 2.31 & 1.78 \\
\hline $50-100$ & 29 & 1.972 & 0.710 & 0.132 & 3.43 & 0.52 & 2.24 & 1.70 \\
\hline $100-150$ & 31 & 1.643 & 0.649 & 0.116 & 2.97 & 0.32 & 1.88 & 1.40 \\
\hline $150-200$ & 31 & 1.327 & 0.492 & 0.088 & 2.33 & 0.32 & 1.51 & 1.15 \\
\hline $200-250$ & 28 & 1.438 & 0.702 & 0.133 & 2.88 & - & 1.71 & 1.17 \\
\hline $250-300$ & 28 & 0.925 & 0.385 & 0.073 & 1.72 & 0.13 & 1.07 & 0.78 \\
\hline $300-350$ & 17 & 1.299 & 0.437 & 0.106 & 2.23 & 0.37 & 1.52 & 1.07 \\
\hline $350-400$ & 17 & 0.822 & 0.413 & 0.100 & 1.70 & - & 1.03 & 0.61 \\
\hline $400-450$ & 23 & 0.615 & 0.307 & 0.064 & 1.25 & - & 0.75 & 0.48 \\
\hline $450-500$ & 10 & 0.360 & 0.401 & 0.127 & 1.27 & - & 0.65 & 0.07 \\
\hline$>500$ & 21 & 0.425 & 0.261 & 0.057 & 0.97 & - & 0.54 & 0.31 \\
\hline
\end{tabular}

TABLE 4

Fundamental Statistical Parameters Calculated for Each 50-Meter Interval Concerning Sediment Fraction A + B $(>93 \mu \mathrm{m})$

\begin{tabular}{|c|c|c|c|c|c|c|c|c|}
\hline \multirow{2}{*}{$\begin{array}{c}\begin{array}{c}\text { Sub-Bottom } \\
\text { Depth } \\
\text { (m) }\end{array} \\
0-50\end{array}$} & \multirow{2}{*}{$\begin{array}{c}\text { Number of } \\
\text { Samples } \\
(n)\end{array}$} & \multirow{2}{*}{$\begin{array}{c}\begin{array}{c}\text { Mean Value } \\
(M)\end{array} \\
3.877\end{array}$} & \multirow{2}{*}{$\begin{array}{c}\begin{array}{c}\text { Standard } \\
\text { Deviation } \\
(s)\end{array} \\
1.341\end{array}$} & \multirow{2}{*}{$\begin{array}{c}\begin{array}{c}\text { Standard } \\
\text { Deviation } \\
\left(S_{m}\right)\end{array} \\
0.268\end{array}$} & \multicolumn{2}{|c|}{$\begin{array}{l}\text { Standard Normal } \\
\text { Distribution } \\
(M \pm t . s)\end{array}$} & \multicolumn{2}{|c|}{$\begin{array}{c}\text { Mean Confidence } \\
\text { Interval } \\
\left(M \pm t . S_{m}\right)\end{array}$} \\
\hline & & & & & 6.64 & 1.11 & 4.43 & 3.32 \\
\hline $50-100$ & 29 & 3.706 & 1.351 & 0.251 & 6.47 & 0.94 & 4.22 & 3.19 \\
\hline $100-150$ & 31 & 3.263 & 1.146 & 1.206 & 5.60 & 0.92 & 3.68 & 2.84 \\
\hline $150-200$ & 31 & 2.479 & 0.794 & 0.143 & 4.10 & 0.86 & 2.77 & 2.19 \\
\hline $200-250$ & 28 & 2.419 & 1.093 & 0.207 & 4.66 & 0.17 & 2.84 & 1.99 \\
\hline $250-300$ & 28 & 1.655 & 0.679 & 0.128 & 3.05 & 0.26 & 1.92 & 1.39 \\
\hline $300-350$ & 17 & 2.105 & 0.732 & 0.177 & 3.66 & 0.55 & 2.48 & 1.73 \\
\hline $350-400$ & 17 & 1.126 & 0.562 & 0.136 & 2.32 & - & 1.41 & 0.84 \\
\hline $400-450$ & 22 & 0.903 & 0.427 & 0.091 & 1.79 & 0.01 & 1.09 & 0.71 \\
\hline $450-500$ & 10 & 0.511 & 0.558 & 0.176 & 1.77 & - & 0.91 & 0.11 \\
\hline$>500$ & 21 & 0.598 & 0.338 & 0.074 & 1.30 & - & 0.75 & 0.44 \\
\hline
\end{tabular}

tude of the changes is much smaller below 300 meters, where compaction and partial dissolution of the biogenic carbonates from the larger sediment fraction are recorded.

The transition from ooze to chalk occurs at approximately 220 meters at DSDP Site 167 in the equatorial
Pacific, the reference section for the Schlanger and Douglas (1974) diagenetic model. At DSDP Site 397, the lithologic boundary between marl oozes and marl chalks (lithologic Units 1 and 2, respectively) occurs at 300 meters. These values are comparable and compatible, the deeper boundary recorded at Site 397 being at- 
TABLE 5

Grain-Size Ratio and Dissolution Ratio Calculated for Each 50-Meter Interval

\begin{tabular}{|c|c|c|}
\hline $\begin{array}{l}\text { Sub-Bottom } \\
\text { Depth } \\
\text { (m) }\end{array}$ & $\begin{array}{c}\text { Grain-Size Ratio } \\
\text { Sed. Fraction } 200-93 \mu \mathrm{m}\end{array}$ & $\begin{array}{c}\text { Dissolution Ratio } \\
\text { Sed. Fraction }>200 \mu \mathrm{m}\end{array}$ \\
\hline $0-50$ & 1.12 & 3.14 \\
\hline $50-100$ & 1.14 & 3.59 \\
\hline $100-150$ & 1.01 & 3.18 \\
\hline $150-200$ & 1.15 & 2.03 \\
\hline $200-250$ & 1.47 & 1.63 \\
\hline $250-300$ & 1.27 & 1.22 \\
\hline $300-350$ & 1.61 & 1.23 \\
\hline $350-400$ & 2.70 & 0.45 \\
\hline $400-450$ & 2.02 & 0.46 \\
\hline $450-500$ & 2.39 & 0.25 \\
\hline$>500$ & 2.47 & 0.39 \\
\hline
\end{tabular}

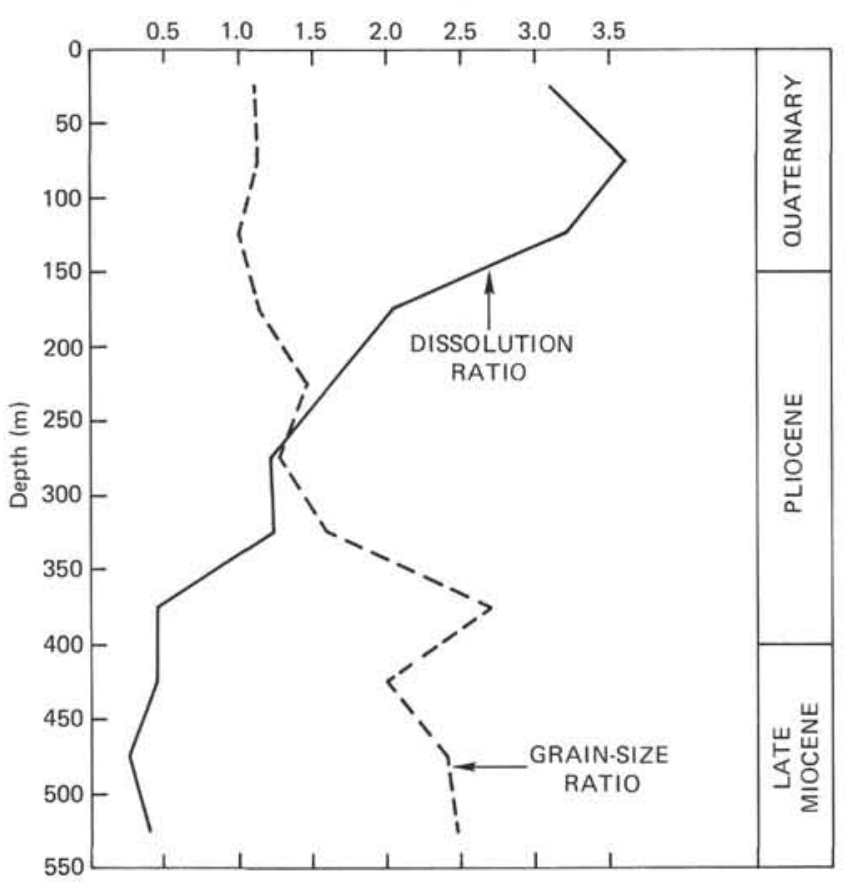

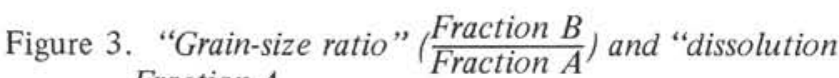
ratio $\left(\frac{\text { Fraction } A}{\mathrm{CaCO}_{3}}\right)$ calculated (mean values) for every successive 50-meter interval. Ratios plotted along horizontal scale.

tributable to the terrigenous dilution also resulting in a higher sedimentation rate.

Berger and von Rad (1972) showed that the CCD rose progressively from the Pliocene to the Miocene in the North Atlantic, reaching its shallowest depth in the middle Miocene. The above assumption apparently contradicts the downward "warming" trend shown by both the carbonate curve, as discussed above, and the isotopic curve (see Shackleton and Cita, this volume). The CCD is known to rise at high latitudes (Berger and Winterer, 1974), the solubility of $\mathrm{CO}_{2}$ decreasing with decreasing water temperatures.
In the lower Pliocene sediments of Site 397, we recorded evidence of downward-increasing dissolution and of downward-increasing temperature, both trends being clearly imprinted in the sediments. The global climatic deterioration characterizing the last $5 \mathrm{~m} . \mathrm{y}$. is superimposed on the evolution of oceanic water masses of the North Atlantic, as will be discussed later (see Cita and Ryan, this volume).

The "dissolution ratio" ranges from a maximum of $3.6(50$ to $100 \mathrm{~m})$ to a minimum of $0.25(450$ to $500 \mathrm{~m})$. It is consistently higher than the "grain-size ratio" in the Quaternary and in the upper Pliocene, whereas from the reversal point located near 250 meters (upper Pliocene) downwards, it is lower than the "grain-size ratio." The total range of the "grain-size ratio" as recorded in the 11 data points curve varies from a minimum of 1 (100 to $150 \mathrm{~m}$ ) to a maximum of 2.7 (350 to $400 \mathrm{~m})$.

In summary, we consider the new parameters defined here useful for discriminating among several factors which can affect sediment properties. These include:

1) Climatic changes which affect both $\mathrm{CaCO}_{3}$ content and Fraction A. Climatic warming results in higher carbonate content and higher productivity of large-sized planktonic foraminifers.

2) Dissolution at depth which lowers Fraction A because of fragmentation of foraminiferal shells and also lowers $\mathrm{CaCO}_{3}$, when strong.

3) Compaction which lowers Fraction A but does not affect the carbonate content.

\section{Statistics}

Figure 5 is a plot of mean values calculated for 50-meter intervals upon which is superimposed the limits of the standard normal distribution and of the mean confidence interval. The standard normal distribution is the interval in which 95 per cent of the observations occur, whereas the mean confidence interval represents the interval in which the "true" mean value falls with a 95 per cent degree probability (Simpson et al., 1960).

The maximum and minimum values of these two intervals were calculated following the usual statistic methodology (see Cavalli-Sforza, 1966), and is formulated as follows:

$$
\begin{aligned}
& \text { S.N.D. }=M \pm t . s . \\
& \text { M.C.I. }=M \pm t . s_{m}
\end{aligned}
$$

where

$$
\begin{aligned}
& M=\text { mean of } n \text { samples from a } 50 \text { meter interval, } \\
& s=\text { standard deviation, } \\
& s_{m}=\text { standard mean deviation } s_{m}=\frac{s}{\sqrt{n}} \\
& t=\text { the value of } t \text { of Student. }
\end{aligned}
$$

The last variable is employed for the calculation of the confidence intervals in cases, as the present one, when the observational data are less than 30 . Once defined, the degrees of freedom (number of observations minus 


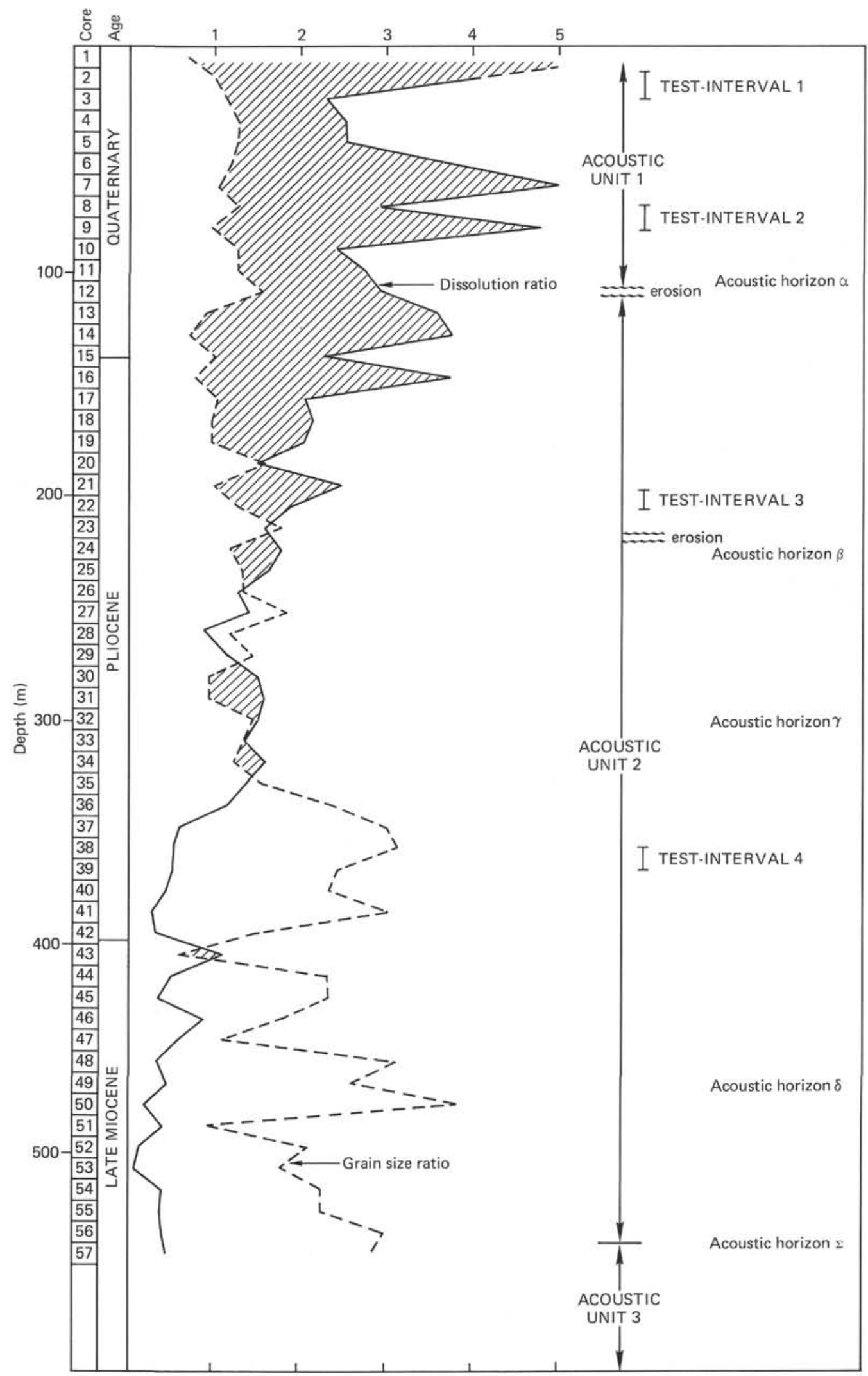

Figure 4. Curve of 57 data points plotting the "grain-size ratio" and the "dissolution ratio" based on averages (calculated core by core) of $\frac{\text { Fraction } B}{\text { Fraction } A}$ and of $\frac{\text { Fraction } A}{\mathrm{CaCO}_{3}}$, respectively. On the right of the figure are plotted the acoustic horizons and acoustic units (after Ryan, this volume) and the test-intervals investigated by quantitative micropaleontological techniques (see Cita and Colombo, this volume). 

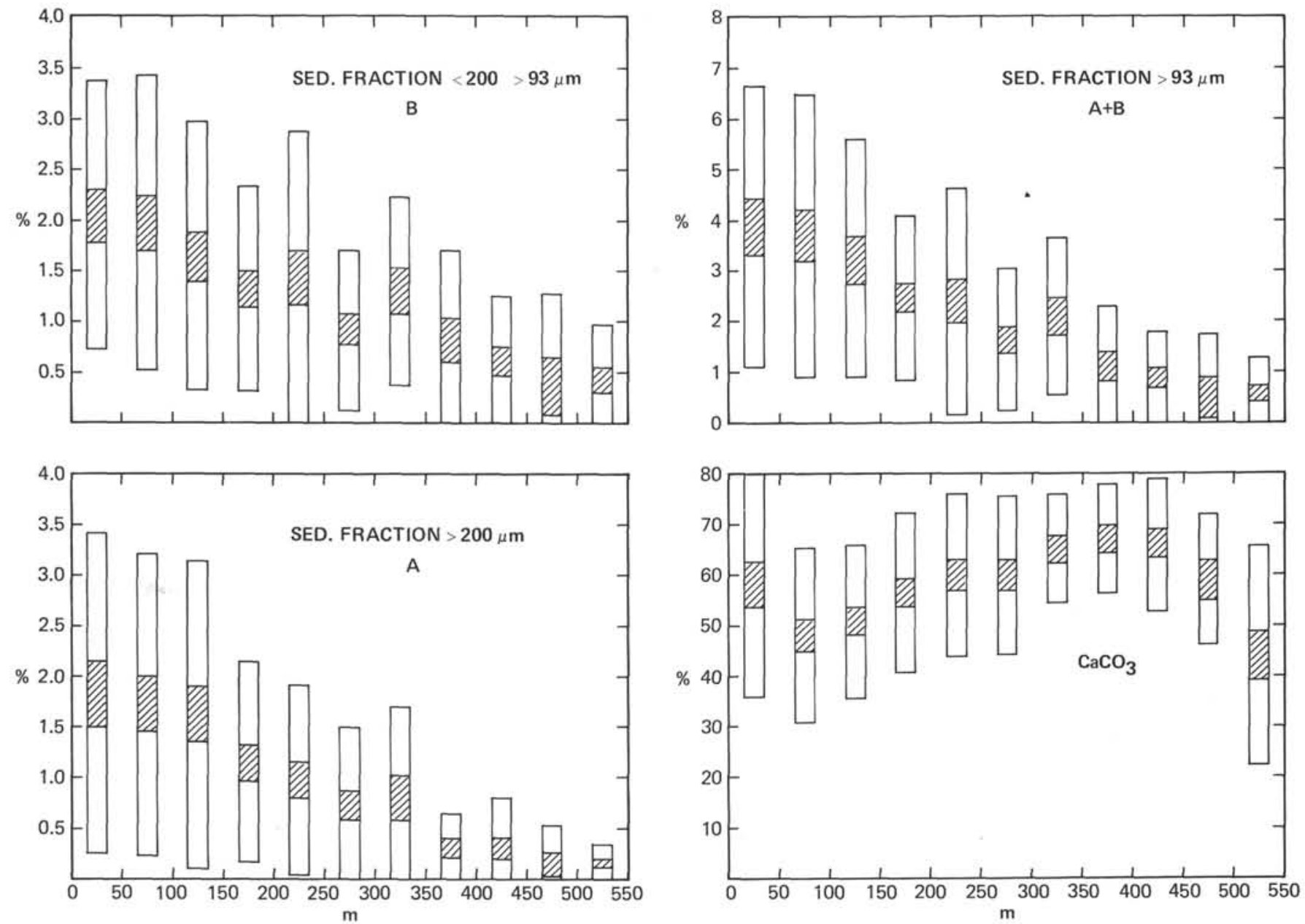

Figure 5. Standard normal distribution (open rectangles) and mean confidence intervals (hatched area) of mean values of sediment Fractions $\mathrm{A}, \mathrm{B}$, and $\mathrm{A}+\mathrm{B}$, and of $\mathrm{CaCO}_{3}$ percentages, calculated for successive 50-meter intervals.

one) and the corresponding value of $t$ can be calculated; for instance, 30 samples correspond to 29 degrees of freedom, that is to say $t=2.045$.

The negative values recorded in the minimum values of the standard normal distribution (calculated in the lowermost interval) are related to (a) the low values of the means, and (b) the subtraction of the standard deviation (s) multiplied for values of $t$ close to 2 . Since these negative values appear illogical, they have been omitted.

\section{Evaluation of the Pyrite "Noise"}

As previously mentioned, both sediment fractions considered here are essentially biogenic. Terrigenous and/or volcanogenic components are minor with a few exceptions, especially in the upper Quaternary. However, authigenic minerals (especially pyrite) are common to abundant in some intervals. Since pyrite was not separated and weighed, one could interpret our grain-size data as meaningless in terms of paleoclimatic indications. To check whether, and to what extent, the percentages of the sediment Fractions A and B were distorted or altered by the occurrence of pyrite, we made a gross visual estimate of the pyrite content (using the standards proposed by Baccelle and Bosellini, 1965), see Figure 6.

The results are as follows:

1) In the 24 samples analyzed from 0 to 50 meters, where the largest percentages for sediment Fractions A and $\mathrm{B}$ are recorded (compare Tables 2 and 3 and Figure $2)$, pyrite is rare.

2) In the 29 samples from 50 to 100 meters, where the percentages of Fractions A and B are the next highest, pyrite is present in variable amounts but never abundant.

3) In the 31 samples from 100 to 150 meters, pyrite is consistently recorded, with a considerable increase below Section 397-13-3. The percentages of Fraction A decrease slowly, whereas Fraction B shows a marked decrease in this same interval.

4) In the 31 samples investigated from 150 to 200 meters, pyrite is common to abundant. The same is true for the following interval. 


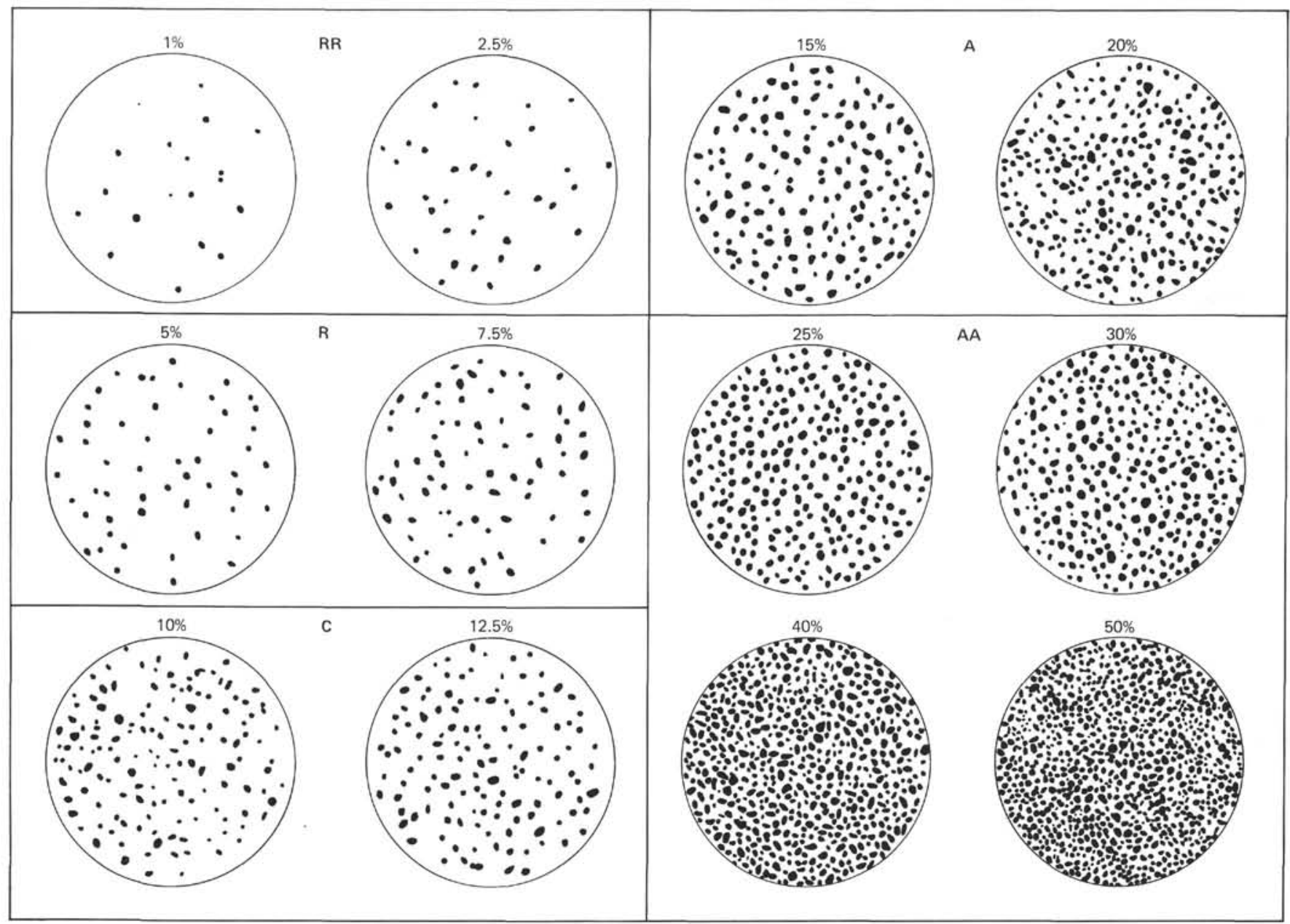

Figure 6. Reference standard for the visual estimate of the abundance of pyrite and other opaque minerals (modified after Baccelle and Bosellini, 1965). $R R=$ very rare, $R=$ rare, $C=$ common, $A=$ abundant, and $A A=$ very abundant.

5) In the 28 samples from 200 to 250 meters, notwithstanding the abundance of pyrite, Fractions A and B continue to decrease downhole.

6) In the 28 samples from 250 to 300 meters, pyrite is abundant down to Section 397-29-6, then it decreases strongly. This rapid decrease in pyrite might be partly responsible for the faster decrease of Fractions A and B in this same interval.

7) In the 17 samples from 300 to 350 meters, pyrite is rare to absent.

8) The same is true for the 17 samples from the interval of 350 to 400 meters sub-bottom. It is significant that in these same intervals, we consistently record a reversal in the general trend of Fractions A and B, with a (slight) increase downhole. A similar reversal is also noticed in the carbonate curve (see Figure 2). In conclusion the "noise" induced by pyrite does not mask a signal which is recorded by (a) grain-size curves, (b) the carbonate curve, and also (c) the isotopic curve (see Shackleton and Cita, this volume).

9) In the 23 samples investigated from 400 to 450 meters, pyrite is again recorded in some abundance, being really abundant in Sections 397-47-4 and 397-47-5. This same interval exhibits a steady decrease in the finer
Fraction B, whereas the coarser Fraction A is possibly affected by the "pyrite noise." The fractions $>200 \mu \mathrm{m}$ are so small at this depth that it suffices to have one single value $>1$ per cent to affect the mean value of more than 20 measurements.

10) In the 10 samples investigated from 450 to 500 meters, pyrite is rare, except for Section 397-52-1, where it is common. Percentages of Fractions A and B continue to decrease, and are extremely small.

11) The 21 samples investigated from Sections $397-52-6$ to $397-57-5$ contain pyrite in variable amounts, but never abundant. Some of the lowest samples contain sediments from the slump interval, where dissolution at depth is less accentuated than in the post-slump interval. This is why the finer Fraction B shows a (slight) tendency to increase.

Based on the above discussion, it appears that the occurrence of pyrite occasionally affects the values recorded, but that by no means does it mask or obscure the signal imprinted in the hemipelagic sediments. Indeed, the interval where the largest amounts of pyrite occur (Cores 397-17 to 397-29) displays a consistent decrease in both the coarse Fraction A and the finer Fraction B. The interval of Cores $397-30$ to $397-42$, where pyrite is 
absent to rare, shows a downhole increase in percentages of these grain sizes.

\section{Construction of Curves From 57 Data Points (mean values determined core by core)}

The 11 data point curves, as discussed above, separate the general trends of the parameters considered from sample noise, but they mask all the minor and some of the major cycles. We, therefore, decided to create a third set of data, averaging the values obtained for each core (see Tables 6 and 7, Figures 4 and 7).

Figure 7 plots the mean values of the percentage weights of sediments (Fractions A, B, and A + B, as defined above) and the percentages of carbonates, calculated for each core. The number of measurements per core ranges from 1 to 6 .

The smoothing effect obtained with the 57 data point curves permits a better identification of the general trend of the "dissolution index" and the visualization of the "dissolution measure" without masking the actual cycles, as shown in the 11 data points curves.

The carbonate curve thus constructed differs from the 260 data point curves. Intervals where high frequency cycles are recorded (i.e., Cores 397-18 and 397-19) appear completely smoothed. Also smoothed is the disturbance related to the Messinian "salinity crisis" in the Mediterranean Sea, an event recorded in the later part of Paleomagnetic Epoch 5, whereas a saw-tooth trend seems to characterize the lower Pliocene.

Table 7 and Figure 4 provide plots of the "grain-size ratio" and the "dissolution ratio." The same general trend shown in Figure 3 is also recorded there, but the resolution is higher. The reversal encountered near 250 meters appears in the 57 data points curve as an interval characterized by marked instability, with a tendency to display an upwards decreasing "grain-size ratio."

\section{SUMMARY OF MAJOR CONCLUSIONS}

The conclusions reached by our quantitative studies on carbonate content, grain-size, and dissolution can be summarized as follows:

1) The carbonate content is essentially biogenic, and is represented by the calcitic tests of (a) Coccolithophorids and (b) Foraminiferids, the latter being mostly planktonic. The mean value of 259 measurements is 57.2 per cent. The range is from 27 to 77 per cent. Both these extreme values are recorded in the upper Miocene, where strong and rapid changes in carbonate content related to dissolution pulses were observed. This high carbonate content is surprising in an upper continental rise setting, where one should expect a high terrigenous input. It is related to high productivity.

2) The frequency of our sampling (one sample/ section, or one every 1.5 meters when core recovery was complete) is such that not all the carbonate cycles known (Hays et al., 1969) can be identified. In fact, with a sedimentation rate averaging $7 \mathrm{~cm} / 1000$ years for the interval under discussion, we have a data point approximately every 20,000 years.
TABLE 6

Mean Values of Fractions A, B, and A+B and Carbonate Content, Calculated for Each Core

\begin{tabular}{|c|c|c|c|c|c|}
\hline Core & $\begin{array}{l}\text { Number of } \\
\text { Sections }\end{array}$ & Fraction A & Fraction B & $A+B$ & $\begin{array}{c}\text { Carbonates } \\
\text { as } \mathrm{CaCO}_{3}\end{array}$ \\
\hline 1 & 1 & 4.40 & 3.10 & 7.50 & 40 \\
\hline 2 & 6 & 2.14 & 2.15 & 4.29 & 52 \\
\hline 3 & 6 & 1.41 & 1.63 & 3.04 & 61 \\
\hline 4 & 5 & 1.53 & 1.95 & 3.48 & 60.5 \\
\hline 5 & 5 & 1.73 & $2.23 / 2$ & $3.96 / 5$ & 67.8 \\
\hline 6 & 4 & 1.71 & 2.02 & 3.73 & 46 \\
\hline 7 & 6 & 2.51 & 2.61 & 5.12 & 50.5 \\
\hline 8 & 6 & 1.49 & 1.92 & 3.41 & 50.5 \\
\hline 9 & 4 & 2.26 & 2.19 & 4.45 & 47 \\
\hline 10 & 7 & 1.17 & 1.49 & 2.66 & 48 \\
\hline 11 & 5 & 1.27 & 1.62 & 2.89 & 46 \\
\hline 12 & 6 & 1.51 & 2.34 & 3.85 & 51 \\
\hline 13 & 5 & 1.92 & 1.71 & 3.63 & $53.3^{\mathrm{a}}$ \\
\hline 14 & 6 & 1.78 & 1.30 & 3.08 & 47.3 \\
\hline 15 & 7 & 1.20 & 1.21 & 2.41 & 52.7 \\
\hline 16 & 6 & 1.93 & 1.51 & 3.44 & 51.4 \\
\hline 17 & 6 & 1.07 & 1.13 & 2.22 & 52.2 \\
\hline 18 & 6 & 1.19 & 1.16 & 2.35 & 55.2 \\
\hline 19 & 6 & 1.10 & 1.08 & 2.18 & 53.4 \\
\hline 20 & 6 & 0.98 & 1.58 & 2.56 & 65.1 \\
\hline 21 & 6 & 1.38 & 1.37 & 2.75 & 56.2 \\
\hline 22 & 6 & 1.18 & 1.52 & 2.70 & 63.1 \\
\hline 23 & 5 & 1.01 & 1.81 & 2.82 & 63.7 \\
\hline 24 & 6 & 1.00 & 1.18 & 2.18 & 56.3 \\
\hline 25 & 3 & 0.91 & 1.20 & 2.11 & 55.8 \\
\hline 26 & 6 & 0.76 & 1.04 & 1.80 & 59.3 \\
\hline 27 & 5 & 0.81 & 1.51 & 2.32 & 64.8 \\
\hline 28 & 6 & 0.51 & 0.61 & 1.12 & 57.6 \\
\hline 29 & 6 & 0.73 & 1.05 & 1.78 & 63.5 \\
\hline 30 & 6 & 0.91 & 0.87 & 1.78 & 60.8 \\
\hline 31 & 4 & 0.84 & 0.80 & 1.64 & 53.5 \\
\hline 32 & 4 & 0.89 & 1.29 & 2.18 & 59.6 \\
\hline 33 & 3 & 0.84 & 1.14 & 1.98 & 62.5 \\
\hline 34 & 7 & 1.03 & 1.26 & 2.29 & 64.4 \\
\hline 35 & 1 & 0.78 & 1.21 & 1.99 & 58.2 \\
\hline 36 & 2 & 0.75 & 1.78 & 2.53 & 65.2 \\
\hline 37 & 4 & 0.42 & 1.27 & 1.69 & 70.4 \\
\hline 38 & 6 & 0.36 & 1.11 & 1.47 & 68.3 \\
\hline 39 & 5 & 0.34 & 0.83 & 1.17 & 65.7 \\
\hline 40 & 1 & 0.28 & 0.67 & 0.95 & 63 \\
\hline 41 & 3 & 0.19 & 0.59 & 0.78 & 68.1 \\
\hline 42 & 2 & 0.22 & 0.33 & 0.55 & 68 \\
\hline 43 & 3 & 0.79 & 0.46 & 1.25 & 72 \\
\hline 44 & 5 & 0.34 & 0.79 & 1.13 & 65.2 \\
\hline 45 & 5 & 0.23 & 0.55 & 0.78 & 65.8 \\
\hline 46 & 1 & 0.55 & 0.99 & 1.54 & 63.8 \\
\hline 47 & 5 & 0.37 & 0.41 & 0.78 & 64.7 \\
\hline 48 & 3 & 0.21 & 0.66 & 0.87 & 64.6 \\
\hline 49 & 3 & 0.28 & 0.73 & 1.01 & 63 \\
\hline 50 & 1 & 0.12 & 0.44 & 0.56 & 62.5 \\
\hline 51 & 1 & 0.23 & 0.22 & 0.45 & 56.2 \\
\hline 52 & 6 & 0.07 & 0.14 & 0.21 & 53.3 \\
\hline 53 & 1 & 0.05 & 0.09 & 0.14 & 62 \\
\hline 54 & 6 & 0.18 & 0.41 & 0.59 & 44 \\
\hline 55 & 5 & 0.17 & 0.39 & 0.56 & 45.3 \\
\hline 56 & 3 & 0.12 & 0.37 & 0.49 & 31 \\
\hline 57 & 5 & 0.22 & 0.63 & 0.85 & 49.3 \\
\hline
\end{tabular}

${ }^{\mathrm{a}}$ The carbonate content was measured on four sections.

3) Fluctuations in the carbonate content are recorded throughout the section, which spans lithologically uniform Tortonian to the Holocene section. The amplitude of these fluctuations is greater in the Quaternary, in the upper Pliocene, and in the uppermost Miocene. Fluctuations are at a noise level magnitude in the lower Pliocene. They are strong, but short in dura- 
TABLE 7

Grain-Size Ratio and Dissolution Ratio Calculated for Each Hole 397 Core

\begin{tabular}{|c|c|c|}
\hline Core & Grain-Size Ratio (B:A) & Dissolution Ratio \\
\hline 1 & 0.70 & 10.99 \\
\hline 2 & 1.00 & 4.12 \\
\hline 3 & 1.16 & 2.31 \\
\hline 4 & 1.28 & 2.52 \\
\hline 5 & 1.28 & 2.55 \\
\hline 6 & 1.19 & 3.79 \\
\hline 7 & 1.04 & 4.97 \\
\hline 8 & 1.28 & 2.96 \\
\hline 9 & 0.97 & 4.81 \\
\hline 10 & 1.27 & 2.43 \\
\hline 11 & 1.27 & 2.76 \\
\hline 12 & 1.55 & 2.95 \\
\hline 13 & 0.89 & 3.5 circa \\
\hline 14 & 0.73 & 3.77 \\
\hline 15 & 1.00 & 2.28 \\
\hline 16 & 0.78 & 3.75 \\
\hline 17 & 1.05 & 2.05 \\
\hline 18 & 0.97 & 2.16 \\
\hline 19 & 0.98 & 2.06 \\
\hline 20 & 1.61 & 1.50 \\
\hline 21 & 0.99 & 2.46 \\
\hline 22 & 1.28 & 1.87 \\
\hline 23 & 1.79 & 1.58 \\
\hline 24 & 1.18 & 1.77 \\
\hline 25 & 1.32 & 1.63 \\
\hline 26 & 1.36 & 1.28 \\
\hline 27 & 1.86 & 1.40 \\
\hline 28 & 1.19 & 0.88 \\
\hline 29 & 1.44 & 1.14 \\
\hline 30 & 0.96 & 1.50 \\
\hline 31 & 0.95 & 1.57 \\
\hline 32 & 1.44 & 1.50 \\
\hline 33 & 1.36 & 1.34 \\
\hline 34 & 1.22 & 1.60 \\
\hline 35 & 1.55 & 1.34 \\
\hline 36 & 2.39 & 1.14 \\
\hline 37 & 2.99 & 0.60 \\
\hline 38 & 3.12 & 0.52 \\
\hline 39 & 2.44 & 0.52 \\
\hline 40 & 2.36 & 0.44 \\
\hline 41 & 3.02 & 0.28 \\
\hline 42 & 1.49 & 0.32 \\
\hline 43 & 0.59 & 1.09 \\
\hline 44 & 2.36 & 0.51 \\
\hline 45 & 2.35 & 0.35 \\
\hline 46 & 1.79 & 0.87 \\
\hline 47 & 1.09 & 0.57 \\
\hline 48 & 3.12 & 0.33 \\
\hline 49 & 2.59 & 0.44 \\
\hline 50 & 3.82 & 0.18 \\
\hline 51 & 0.93 & 0.41 \\
\hline 52 & 2.10 & 0.13 \\
\hline 53 & 1.77 & 0.08 \\
\hline 54 & 2.26 & 0.41 \\
\hline 55 & 2.26 & 0.38 \\
\hline 56 & 2.97 & 0.40 \\
\hline 57 & 2.83 & 0.45 \\
\hline
\end{tabular}

tion, and related to dissolution pulses in the upper Miocene.

4) Averaging the values at different scales, we were able to clarify the major trends. We have a definite trend towards increasing values of $\mathrm{CaCO}_{3}$ as a function of time from the Quaternary to the lower Pliocene. Near the Miocene/Pliocene boundary, we have a clear re- versal of trend, which is considered climatically significant, inasmuch as it coincides with similar reversals recorded in grain size and in isotopic composition trends.

5) We consider the carbonate content to be climatically significant. This is shown by correlation with the results of quantitative micropaleontological studies on four selected test intervals from the upper Quaternary, the lower Quaternary, the upper Pliocene and the lower Pliocene (see Cita and Colombo, this volume). It is also demonstrated by investigations on stable oxygen and carbon isotopes in benthic foraminifers. selected from the same set of samples (Shackleton and Cita, this volume). High $\mathrm{CaCO}_{3}$ values correlate with high percentages of tropical and/or subtropical faunal elements and with low percentages of polar and/or subpolar elements. The trends towards increasing carbonate values correlate with isotopic lightening.

6) Downhole decreasing values of carbonate within the Miocene are not considered climatically significant, but are due to dissolution at depth. Extended fragmentation of foraminiferal shells, low P/B ratios, enlargements of foraminiferal pores are recorded, along with a strong decrease of larger sediment Fraction A. This shallowing of the CCD as a function of time in the Miocene is consistent with previous findings in the North Atlantic (Berger and von Rad. 1972).

7) The two grain sizes considered (Fraction $\mathrm{A}=$ $>200 \mu \mathrm{m}$; Fraction $\mathrm{B}=200$ to $93 \mu \mathrm{m}$ ) also show fluctuations throughout the interval considered. As for the carbonate content, fluctuations are of larger amplitude in the upper Quaternary, where they appear to be climatically modulated.

8) We defined the inverse of the relative abundance (expressed in percentage weight) of sediment Fraction A as the "dissolution index." The "dissolution index" increases downhole as a function of depth. This general trend is similar to the trend shown by the carbonate curve and by the isotopic curve, both of which tend to increase downhole at least to the Miocene/Pliocene boundary. Also a detailed examination shows grain-size and carbonate curves tend to have an opposite trend. This agrees with quantitative observations on Core $\mathrm{V}$ 28-239 in the equatorial Pacific (Shackleton and Opdyke, 1976).

9) We defined as "dissolution measure" the difference in percentage weight between Fractions $A$ and $B$, as defined above. In general, Fraction $\mathbf{A}$ is smaller than Fraction B (negative dissolution measure). The differences are small in the Quaternary and in the upper Pliocene. They are much greater in the lowermost part of the section, where we have strong evidence of dissolution. Fragmentation of foraminiferal tests results in an increase of Fraction B versus the larger Fraction A.

10) We consider the rare intervals where the "dissolution measure" is positive as perturbations in the oceanographic regime at the drillsite.

11) We defined as "grain-size ratio" the ratio between sediment Fractions B and A. This parameter is steady in the upper part of the succession, where the diagenetic potential of the sediments (sensu Schlanger 


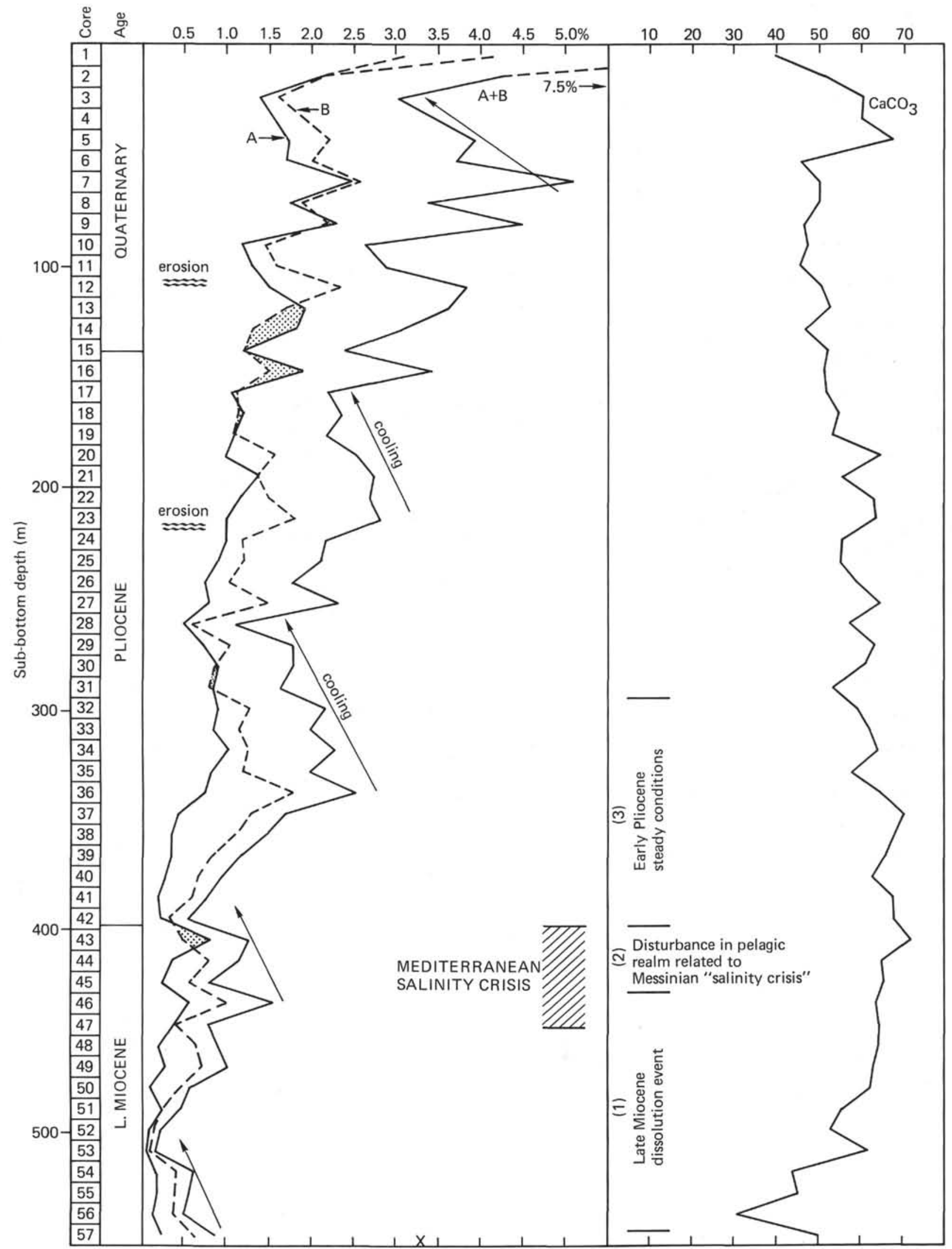

Figure 7. Curves of 57 data points plotting the mean values (core-by-core) of sediment Fractions $A, B$, and $A+B$, and of the $\mathrm{CaCO}_{3}$ content. 
and Douglas, 1974) is highest. It tends to increase downhole. Marked fluctuations are recorded in the lower Pliocene and in the upper Miocene. The range of this parameter, based on core-by-core averages, is from 3.7 to 1.2 .

12) We visually evaluated (i.e., in a non-quantitative way) the disturbances induced by pyrite and other opaque authigenic minerals, which are locally present in some abundance. From this we conclude that the pyrite noise occasionally masks, but never obliterates, the climatic message imprinted in the sediments. In particular we demonstrated that some intervals where strong fluctuations in grain-size occur, as the lower Pliocene, are consistently devoid of pyrite.

13) We defined as "dissolution ratio" the ratio between sediment Fraction A and the carbonate content (\%). This parameter displays a trend which is opposite with respect to the "grain-size ratio," and tends to decrease downhole as a function of depth. Its range, based on core-by-core averages, is from 5 to 0.1 .

14) We consider the introduction of these parameters, starting from simple, observational, and strictly quantitative data, as very useful for interpreting the evolution of ocean paleoenvironment (see Cita and Ryan, this volume).

15) We strongly recommend that the procedures followed here be applied to the investigation of other continuously cored upper Neogene successions from deep-sea sediments, to compare their paleoceanographic evolution.

\section{ACKNOWLEDGMENTS}

The present research was partially funded by Consiglio Nazionale delle Ricerche of Italy, Comitato 05 and partly by Ministero della Pubblica Istruzione, through grants to M.B.C.

We gratefully acknowledge technical assistance by Alberto Malinverno.

An early draft of the present text was critically read by W. B. F. Ryan, U. von Rad, N. Shackleton, and L. Diester-Haass. Discussions with N. Fantini Sestini, E. Robba, I. PremoliSilva, and W. B. F. Ryan were of great help.

We gratefully acknowledge M. Gnaccolini, University of Milano, and A. Rizzini, AGIP-AMI, San Donato Milanese, for their careful review and suggested improvements to the text.

\section{REFERENCES}

Baccelle, L. and Bosellini, A., 1965. Diagrammi per la stima visiva della composizione percentuale nelle rocce sedimentarie, Annali Univ. Ferrara, N. S. Sez. IX, v. 1, p. 59-62.

Berger, W. H., 1968. Planktonic foraminifera: selective solution and paleoclimatic interpretation, Deep-Sea Research, v. 15 , p. $31-43$.

Berger, W. H. and von Rad, U., 1972. Cretaceous and Cenozoic sediments from the Atlantic Ocean. In Hayes, D. E., Pimm, A. C., et al., Initial Reports of the Deep Sea Drilling Project, v. 14: Washington (U.S. Government Printing Office), p. 787-954.

Berger, W. H. and Winterer, E. L., 1974. Plate stratigraphy and the fluctuating carbonate line, IAS Special Publ., no. 1, p. 11-48.

Cavalli-Sforza, L., 1966. Analisi statistica per medici e biologi e analisi del dosaggio biologico, Torino, Berlinghieri.

Cita, M. B., 1971. Biostratigraphy, chronostratigraphy and paleoenvironment of the Pliocene of Cape Verde (North Atlantic), Rev. Micropaleontologie, v. 14, p. 17-32.

Diester-Haass, L., 1976. Late Quaternary climatic variations in Northwest Africa deduced from East Atlantic sediment core, J. Quaternary Res., v. 6, p. 299-314.

Hays, J. D., Saito, T., Opdyke, N. D., and Burckle, L. H., 1969. Pliocene-Pleistocene sediments of the equatorial Pacific: their paleomagnetic, biostratigraphic, and climatic record, Geol. Soc. Am. Bull., v. 80, p. 1481-1514.

Johnson, D. A., Ledbetter, M., and Burckle, L. H., 1977. Vema Channel paleo-oceanography: Pleistocene dissolution cycles and episodic bottom water flow, Marine Geology, v. 23, p. 1-33.

Schlanger, S. O. and Douglas, R. G., 1974. The pelagic oozechalk-limestone transition and its implications in marine stratigraphy, IAS Special Publ., no. 1, p. 117-140.

Shackleton, N. J. and Opdyke, N. D., 1976. Oxygen-isotope and paleomagnetic stratigraphy of Pacific Core V 28-239: late Pliocene to latest Pleistocene, Geol. Soc. Am. Mem. 145 , p. $449-464$.

Simpson, G. G., Roe, A., and Lewontin, R. C., 1960. Quantitative zoology: New York (Burlingame).

Thiede, J., 1977. Aspects of the variability of the glacial and interglacial North Atlantic eastern boundary current (last 150,000 years), "Meteor"' Forsch.-Ergebnisse, R. C., no. 28, p. 1-36. 